Daniel Hiernaux-Nicolas (2015)

\title{
Turismo, sociedad y territorio: una lectura crítica. Libro Homenaje a Manuel Rodríguez Woog (1957-2015)
}

Querétaro, Universidad Autónoma de Querétaro

\author{
Felipe Cuamea Velázquez \\ Facultad de Economía y Relaciones Internacionales \\ Universidad Autónoma de Baja California (UABC) \\ cuamea@uabc.edu.mx
}

$\mathrm{N}$ os convoca la presentación de un libro concebido como un "no-libro" con una introducción que no lo es, y se realizó "a manera de introducción”, así que solo me resta escribir esta no-reseña de Turismo, sociedad y territorio: una lectura crítica. Libro homenaje a Manuel Rodríguez Woog (1957-2015). Este no-libro es un extraordinario y encomiable esfuerzo de coordinación a cargo de un destacado académico y analista crítico de los temas que en él se abordan: Daniel Hiernaux-Nicolas. Esta obra conjunta una serie de textos especializados y cumple con dos propósitos fundamentales: el primero, brindar un homenaje a Manuel Rodríguez Woog, protagonista en muchos sentidos del quehacer del turismo en México: en su vertiente profesional como funcionario público, analista, consultor, conferencista, profesor, escritor, empresario, crítico contumaz, y en el ámbito de lo personal: amigo, colega, estudiante y académico, correligionario, provocador, activista, recepcionista, encuestador, organizador de eventos, el de largas sesiones de lectura y discusiones casi interminables; lector ávido, admirador de las ideas antiescolarizantes de Iván llich, fumador empedernido de Fiesta, Baronet y Raleigh, encaminador de almas, aquel de la duda sistemática y el juicio agudo, la sonrisa inefable bordeando el filo de la complicidad o la ironía; compañero de aventuras creativas, recreativas e intelectuales y muchas otras facetas que pudieran caracterizar a Manuel (José Antonio) Rodríguez Woog, en síntesis, como un homo ludens a la manera de Johan Huizinga. A saber.

En segundo lugar, este texto nos ofrece una gama de investigaciones y discusiones más recientes en vertientes diversas del turismo retomando las inquietudes académicas e intelectuales que hace ya más de tres décadas fueron el centro del interés y formación de una generación de la que Manuel Rodríguez Woog fue pieza clave.

La excelente no-introducción de Daniel Hiernaux da cuenta clara y sucinta de las 22 contribuciones que aglutinan a más de una treintena de especialistas en los cuatro grandes ejes que guían la obra y que permiten abordar los ámbitos en los que se ha desarrollado la investigación y discusión académica y profesional del turismo: 1) Conceptualizando el 
turismo y su desarrollo, 2) Éxitos y fallas: las paradojas del turismo tradicional, 3) En busca de un turismo alternativo, y 4) Lecciones de experiencias internacionales.

La primera parte, "Conceptualizando el turismo y su desarrollo", retoma la discusión de conceptos que hace ya más de tres décadas marcaron a una generación de estudiantes y estudiosos del turismo que buscaban afanosamente que el análisis de este fuera considerado como "algo serio": la reconceptualización del sistema turístico en sus formas más complejas; la industria turística con sus nuevos actores y tendencias tecnológicas y la aún incompleta conciliación del turismo con el espacio natural y la sustentabilidad como ejes de las políticas del sector. En esta búsqueda de renovadas concepciones del turismo y sus protagonistas adquiere relevancia el papel de la subjetividad, las fantasías e imaginarios de los viajantes, el sentido quizá moderno del significado de lo "exótico” y el retorno a la naturaleza.

En la segunda parte, "Éxitos y fallas: las paradojas del turismo tradicional”, se analiza la puesta en marcha y las experiencias resultantes de importantes proyectos de desarrollo turístico en diversas regiones del país con predominancia del binomio sol y playa como anclaje principal, incluyendo centros integralmente planificados (CIP) como Cancún, y otros destinos tradicionales como Acapulco, además de zonas y corredores de desarrollo costeros. Las contribuciones de este capítulo evidencian las paradojas y contradicciones resultantes del despliegue de importantes políticas públicas para financiar con inversiones inimaginables ambiciosos proyectos que llevarían el progreso y bienestar a la población, que transformarían las regiones más atrasadas del país, a partir de la premisa de que el turismo, la "industria turística" era, por su naturaleza, una actividad económica inocua, altamente generadora de empleos, compatible con los recursos naturales como atractivo central: playa, arena. Tras décadas de impulso a la visión predominante y desarrollista del turismo se han originado enormes desigualdades económicas y sociales, enclaves económicamente rentables pero aislados del entorno, según se desprende de los resultados que reportan los estudios de caso. Ninguna política pública, por supuesto, es malintencionada. Las acciones, sin embargo, suelen seguir el rumbo de las ideas que las sustentan.

En la tercera parte, "En busca de un turismo alternativo", se retoman y revisan viejos conceptos pero en versiones más actualizadas para realidades cambiantes, con un dejo de optimismo esperanzador en la búsqueda del turismo alternativo, donde las estructuras sociales y culturales en las áreas receptoras y la población se conviertan en protagonistas activos en nuevas formas de planificar, gestionar y operar las actividades turísticas, con opciones y motivaciones de viaje que revaloren la importancia del ocio como disfrute de la cultura; un modelo alternativo que haga posible y plausible el desarrollo de las comunidades indígenas, un modelo de turismo compatible con el desarrollo rural y la conservación de los recursos naturales. Explorar nuevas maneras de hacer turismo, o revisarlas desde nuevas perspectivas, también vale la pena como parte de una agenda más amplia y ambiciosa en la búsqueda de (un) turismo alternativo. 
El cuarto y último apartado recoge varias experiencias internacionales, desde las transformaciones en la sociedad argentina a principios del siglo xx y su impacto en la interacción social en la moda vacacional de las playas, así como la paulatina incorporación de la mujer en otros aspectos de la vida social antes reservados a los hombres, hasta la noción de la mujer como un "atractivo" más en las playas argentinas. Se ofrece también el caso del modelo de desarrollo turístico de enclave o al estilo del desarrollo inmobiliario hotelero en las Islas Baleares exportado "exitosamente" a países como México, y que hoy se denomina la balearización del turismo, en alusión directa a los efectos ambientales y sociales nocivos derivados de ese modelo turístico, además de un trabajo en torno a las diversas formas de interacción social entre turistas y población residente, y las percepciones respecto de los impactos del turismo en diversas dimensiones y cómo incide tal valoración sobre la actividad turística.

Difícilmente un libro (en este caso, un no-libro) puede agotar una agenda de investigación o indagación, sin embargo, este nos presenta en perspectiva los conceptos e ideas que constituyen la veta intelectual y académica que interesó y para la cual vivió Manuel Rodríguez Woog. Se cumple así cabalmente con el reconocimiento y homenaje. Quedan trazadas algunas líneas para proseguir con la búsqueda académica e intelectual, aunque solo sea para el encuentro simple y pleno con el ocio. 